\title{
Resource Mobilization and Elections
}

1Fatemeh Ghanai

\author{
2Nourallah Gheysari
}

\author{
${ }^{2}$ Kiamars Jahangir \\ ${ }^{1}$ PhD Student in Political Science (Political Sociology), Tehran University \\ ${ }^{2}$ Assistant Professor of Tehran University; Email: ghanaifatemeh@yahoo.com
}

\section{Doi:10.5901/mjss.2016.v7n4s2p240}

\section{Abstract}

The present research has been carried out with the objective of identification and determination of the effect of difference in the type of resources available to candidates on the victory of one candidate over other competitors. Two hypotheses have been used in order to achieve the above objective. The theoretical framework of research is based on theories and models which exist in the field of electoral behavior analysis where three perspectives are more prominent than other theories which are the sociological model, Psychological-political model and rational selection model (rational choice). Election is one of the most influential political phenomena in democracy systems. The prediction of election results and the chosen person is greatly important for both the political system and candidates' fans and people. The main hypothesis of research is that "there is a relation between the use of a type of resource mobilization available to the candidate and the victory of one candidate over other competitors" and the objective of this study is identification and determination of the type of available resources for candidates and its relation with the victory of one candidate over other competitors using the approach of resource mobilization and its theories. This is a documentary and library research which reviews the relationship between resource mobilization (independent variable) and elections (the dependent variable). In general, Pearson correlation test was used to determine the relationship between independent and dependent variables where all four hypothesis of the research had moderately extreme relationship which was also obtained to be significant and the multivariate regression test was used to determine the level of effectiveness of independent variables on the dependent variable which was obtained using enter method. The value for multivariate regression correlation coefficient $(R=0.786)$ indicates strong correlation between the set of independent variables and the dependent variable. The value for Coefficient of determination $(R 2=0.618)$ indicated the above average ratio of dependent variable variance explained by four independent variables of the research. This means that by inclusion of all independent variables, about 62 percent of the variability of the victory of a candidate over to other competitors is determined by these factors.

Keywords: mobilization, resource mobilization, election, resource mobilization and election

\section{Introduction}

Incentives to participate and vote are related to economic, psychological, political and social fields. Based on the economic incentives, people vote in order to cut costs and increase their benefits. Psychologists believe that psychological characteristics of people are determinant of their voting behavior. They believe that people have different personality and psychological characteristics which makes them interested or discouraged about political participation. Effectiveness and political trust is also one of the reasons based on which people feel they can influence the political process to some extent and affects their voting behavior. Also people with more confidence in their political system are more likely to participate in elections. Individual and social position and characteristics of people in social aspect such as gender, age, education level and income determine their voting behavior.

Election can be consider as one of the most influential political phenomena especially in democracy systems. Elite rotation, changes in policies and strategies, changes in political discourses and attitudes are among evident changes which can be observed with elections. Elections in presidential systems always has more importance and sensitivity than other elections due to place and the role that the executive branch has. Prediction of election results and the winner is generally important for both the political system and the supporters of the candidates.

The main objective of this article is answering this question that how is the identification of determination of the type of resources available to candidates and its relation with the victory of one candidate over other competitors? We 
initially must have a clear definition about this matter in order to be able to answer this question. In this study, the researcher is seeking to find out how one must mobilize factors affecting the success of a candidate over other competitors in order to achieve the final victory and here, resource mobilization and management of resource mobilization are greatly important.

There are objections in review of researches which have been carried out in this field until now and the researchers tried to carry out this study completely and put shortcomings and flaws of other carried out researches aside. The research method has not been selected properly in some of the mentioned projects or the source of assumptions in not specified in most of the mentioned projects and the fact that which theory or model is used is not clear. The proposed models are mainly repeated western models and no significant innovation can be observed in them. Some of them have only paid attention to the issue of political participation and have discussed the discussed and have not mentioned the method of resources mobilization in order to have victory over other competitors. Some of them have measured only one contributing factor for example the effect of advertising in radio and television on increasing the success of a candidate or the effect of party disposition on the victory of one candidate and there is no research which completely evaluates all affective factors from different aspects of the issue of resource mobilization.

Four hypotheses have been developed to achieve the objective of the mentioned issue which are derived from theoretical framework and cover all parts of the issue in terms of political resources, cultural resources, economic resources and social resources. A researcher-made questionnaire containing 15 questions which its validity has been confirmed by elite teachers and its reliability has been estimated to be approximately $89 \%$ using Cronbach's alpha has been used to carry out the research which has been distributed among the one hundred individuals among the statistical population including elite professors of Tehran University, Allameh University and Imam Sadeq University in order to collect the intended data. Pearson correlation and multivariate regression were used to analyze the data after entering the questionnaires into the SPSS software in order to answer the main matter of the article.

Pearson correlation test has been used to determine the relation between dependent variables and the dependent variable and the multivariate regression test has been used to determine the effectiveness of independent variables and the dependent variable.

\section{The Importance and Necessity of the Research}

The necessity and importance of this study is to an extent that Paul Lazarsfeld and his research team concluded by studying the correlations between socio-economic characteristics on one hand and behavior of voters on the other hand that the method of people's voting results from "political socialization" to a great extent and the meaning of political socialization here is the methods and tools for perpetuation of political culture of a society and is in fact a consistent longterm process which forms a part of training and preparation of each member of society (Alikhani, 1998: 20). Political socialization is necessary and vital for durability and stability of the government.

\section{Research Hypotheses}

\subsection{The main hypothesis of research}

There is a relation between the use of resource mobilization available to the candidates and the victory of one candidate over other competitors.

\subsection{Secondary research hypotheses:}

1) There is a relation between the use of political resources available to the candidates and the victory of one candidate over other competitors.

2) There is a relation between the use of cultural resources available to the candidates and the victory of one candidate over other competitors.

3) There is a relation between the use of economic resources available to the candidates and the victory of one candidate over other competitors.

4) There is a relation between the use of social resources available to the candidates and the victory of one candidate over other competitors. 


\subsection{The objectives of research:}

\subsubsection{The main objective:}

Identification and determination of the type of resources available to candidates and its relationship with the victory of one candidate over other competitors.

\subsubsection{Secondary objectives of research:}

- Identification and determination of the type of political resources available to candidates and its relationship with the victory of one candidate over other competitors.

- Identification and determination of the type of cultural resources available to candidates and its relationship with the victory of one candidate over other competitors.

- Identification and determination of the type of economic resources available to candidates and its relationship with the victory of one candidate over other competitors.

- Identification and determination of the type of social resources available to candidates and its relationship with the victory of one candidate over other competitors.

\section{Research Method}

Since this research has been carried out to describe and explain, Survey Method was determined to be more appropriate. Furthermore, documentary method was used in evolution of conceptual and theoretical aspects which form the research literature. Elite political science professors of Tehran University, Shahid Beheshti University and Allameh University form the statistical population of the present study. The sample size in this study has been calculated to be 100 individuals using Cochran formula.

Questionnaire was considered as the most appropriate practical method for data collection, thus, Likert scale (scores summing method) was used in preparation of questionnaire and its adjustment and configuration. Taking notes has been used as the collection tool in literature concept and theoretical research. The validity of the tools of this research was determined using armchair validity (referral to teachers) and Cronbach's alpha was used -the alpha of whole questions was estimated to be about $89 \%$ - for its reliability. Which indicate the stability of questions and the acceptable internal cohesion.

Ultimately, Pearson correlation test was used to identify the relation between independent variables and the dependent variable and multivariate regression test was benefited from to assess the effect of independent variables on the dependent variable.

\section{The Definition of Concepts and Words}

\subsection{Mobilization}

The word Mobilization means Division draw (Aryanpur, Manouchehr, 2006, p 490). The term mobilization is one of the main characteristics is the phenomenon of revolution which means preparing groups for a collective action. The collective action can be defined as individual actions which act together to pursue common interests. In the meantime, mobilization includes ways by which one group can control the adequate resources to enable collective action. These resources include reserves of material goods, political support or weapons and military equipment and information (Giddens, Anthony, 2002: p. 671).

\subsection{Resource Mobilization}

Resource Mobilization theory was initially raised to analyze individual choices and organization of social movements but those who are currently working on this theory increasingly pay attention to creation of collective identities and challenging social events and issues. This theory begins with liberal individualism (Nash, Kate, 2001: p. 130). 


\subsection{Election}

The word "election" is from the Arabic verb root of "Nakhaba" means the selection and choice and its English equivalent which is Election is from the Latin verb root of Eligeve which means separating, disassembling and adopting. This word has had a broad changes and developments of sense in terms of semantics but its general and common application means a way or method for selecting a certain number of individuals from a large number of those who become candidate for having a position or a role.

It has been stated in another definition of election that: "election is a set of actions which have been planned for selection of rulers or determination of supervisors for power skill".

From this perspective, election is a tool by which we can determine the will of the citizens in the development of political institutions and determination of political exercise authority in charge of the intervention.

In fact, the voter participates in management of political affairs of his/her society by selecting a representative or representatives. In fact, the members of the society are directly and indirectly involved in shaping public policy through the election. Elections acts individually or collectively, in group or guild along with other mechanisms of citizen participation and it is also the most obvious and the most measureable kind of participation of people in the political field. In addition, election shows the social bases of political power on one hand and is a good criterion to evaluate the distribution of power in society on the other hand (Daraie, 2009: 20).

\section{Variables of the Research and Method of their Evaluation}

\subsection{The independent variables of the research}

Mobilization of resources

\subsection{The Dependent variable of the research}

The victory of one candidate over other competitors

\section{Research Background}

Political participation has been studied in different ways. Reviewing other researches carried out in relation to the subject of the research is greatly important in any research. Reviewing these researches can inform the researchers about the process of research of other individuals as well as the quantity and quality of their researches so that they can be more familiar with advantages and disadvantages of other carried out works and can advance better in development of the subject of the research and research processes. Also, the comparison done by researchers in different researches can clear some of the issue which are not discovered by others. Some of the researches which have the greatest intercourse with the subject of the research have been mentioned in this section.

Emam Jom'ehzadeh et al (2012) evaluated the relation between social capital and political participation among students of Isfahan University. The statistical sample of this research consisted of 188 students of Isfahan University. The results show that there is a significant correlation between aspects of social capital and political participation of students.

Jahangiri and Abutorabi Zarchi (2012) evaluated the effect of the level of using mass media on the components of the political culture of students of Shiraz University. Their statistical sample consisted of 430 students of Shiraz University and their research findings have shown that there is a significant positive relationship between using radio, local TV, newspapers, magazines and political and cultural factors (values, beliefs and political passions). Also a significant negative relationship can be observed between political culture components and the level of using Internet and satellite.

Hersij et al (2011) evaluated the effects of Media consumption on Political participation of students of Isfahan University. The Statistical population of this research consisted of 188 students of Isfahan University. The research findings show that there is a significant correlation between consumption of mass media and political participation of respondents.

Sheikholeslami and Asgarian (2009) evaluated the issue of constructivism, media and electoral behavior in Iran. They state by evaluation of highlighted role of the media in the formation of different layers that the National media can and should create awareness and concern about the problems of society in people and force them to participate in determining their own destiny by encouragement and motivation of diverse groups of people to participate in elections, especially groups such as the Silent and indifferent majority / minority who are either those who do not care about 
elections and politics or those who do not have independent opinions and views from the media and follow the thoughts of others.

Ismaili and Movahedian (2009) evaluated the subject of elections in the Islamic Republic and the role of national media in it. They found out in this research that since the Islamic republic is a democracy based on religion, the position of media in realization of political participation in general and the functioning of the national media in the Islamic Republic in particular reveal the doubled and decisive importance of the national media in different elections.

Fairuz Hajian and Jahangiri (2008) evaluated the sociological analysis of political participation of students of the Tehran University. The statistical sample of this research consisted of 379 students of Tehran University. Findings have shown that there is a significant relationship between 16 independent variables in this research (Age, gender, marital status, mother's education, father's education, father's occupation, employment status of the mother, the person's location, socioeconomic status, type of college, political family, political friends, participate in forums, religious commitment, use of mass media and media trends) and political participation of students.

Panahi and Alizadeh (2005) evaluated the effect of mass media on political participation of citizens. Their research findings have shown that the media indirectly affect the political participation through factors such as political culture, political efficacy and political incentives to influence political participation in the long run.

Nesbitt Larking evaluated the effect of media on electoral behavior in Canada and have compared it with the electoral behavior in the United States. The findings of this research indicate the major distinctions between the United States and Canada regarding the election campaign in the media in the two countries. This means that electoral campaigns in Canada are Party-driven but in America, focuses are on the personality characteristics of candidates for vote collection (quoted by Jahangiri and Abu Torabi Zarchi, 2012).

McCombs and Shaw evaluated the effect of media on election. The results of their study has shown that media have a deep impression on voters through Special and exaggerated news coverage and provoke them to vote for a certain candidate in addition to participation in elections (quoted by Sheikholeslami and Asgarian, 2009).

\section{Theoretical Foundations of the Research}

The theoretical framework of this research is composed of different theories that each have focused on political culture form several different aspects and each have raised and evaluated their intended variables and concepts in effectiveness on political culture.

\subsection{The patterns of Political culture}

Almond believes that the Political culture affects the frameworks, institutions, practices and political stability of the system. The political culture is passed to a new generation in any society through the process of political socialization and through the family, school, mass media and peer groups (Rush, 1998: 60). In fact, Almond and Verba point out the macro element of society which is the culture by raising the political culture which is the director of most other elements of society, so in summary we can say that all variables which exist in socialization can affect the political culture, socioeconomic status, ethnicity, education, political motivation, personality type which forms in the society and social status in the society in which the person lives are factors which can effectively determine people's political culture.

\subsection{Sociological pattern}

The main Sociological pattern of electoral behavior's analysis has been released by the American Paul Lazarsfeld who was a sociologist at Columbia University and his research groups in the 40s. They concluded in their field researches that the effect of advertising on voters is very low and the extensive advertising of parties do not have any effect on voters in practice and they have made their decision long before the start of electoral campaigns. In other words, sociologists believe that Structure and status affect people's political orientations and they have constant tendencies which are rooted in the family environment, career and cultural environment (Ayoubi, 1998: 16).

Paul Lazarsfeld and his research team concluded with studying the existing correlations between socio-economic characteristics on one hand and the behavior of voters on the other hand that the voting of people is to a great extent the result of "political socialization" and the political socialization here means a Method and tool for perpetuation of political culture and is in fact a long term and continuous process which forms a part of the training and preparation of each member of society (Alikhani, 1998: 20). Political socialization is a necessary and vital matter for durability and stability of the government. 
Political socialization gradually instills prevailing values and common political system to a person and enables that person to establish a relationship with the system and the person and the government can understand each other's expectations through it (Ariaie, 1997: 121).

"Political socialization" helps in survival and legitimacy of the political system and the government and aids the system by preparing and training its members to obey the commandments and fulfill their roles. In other words, the system has a successful role in scope and extent which is provided by socialization because will follow the rules and accept diverse role such as judge, police, candidate, and voter and ... in order to maintain the normal process of the system. In a more complex concept, people have become Sociable is a way that they sometimes observe laws which have been approved by representatives whom they have not voted for or is executed by a president not accepted by that person with no sense of obligation (Alikhani, 1998: 120).

Paul Lazarsfeld and his research group showed that the political orientation of the voters can be easily predicted by studying the social, economic and cultural status of them. Because there is a direct connection between social conditions and political orientation and social characteristics determine the political characteristics of individuals.

Lazarsfeld believes that a person politically thinks in a way that he/she socially lives. So the social factors determine the political tendencies of people (Lazarsfeld, 1994: 27).

The main attention in this pattern is to social structures and individual decisions and personal motives were focused less in analyses of this method. Variables such as religion, age, social class and even local geography determine the vote of people, they emphasis on this general principle that relations of a person in initial groups will form the political and fundamental relations in him/her by emphasizing on the learning theories (Hormoz, 1999: 103).

Culture, social groupings, the mass media are among other public institutions of political socialization. This method is still considered by political researchers in the various theories and it used for drawing electoral maps of countries. This approach is more favored among researchers of electoral behavior compared to other approaches and patterns but it should not be forgotten that there are different views and arguments in this approach. Group membership of the selector person, social class, religious affiliation, geographic and ethnic ties and finally age and gender are greatly important in this approach, it can be said that sociological analysis on focus individual incentives less and explain the continuity and stability of the political tendencies of different geographies using factors that are beyond the person. In this view, social and cultural structure and social context and even geographical structure join hands and create a special tendency in one region (Ayoubi, 2003: 19).

The perspective of Durkheim should also be mentioned in the sociological pattern (1968: 56), based on this pattern, he believes that if some grab the political power, they will form a territory which is out of the reach of others. On the contrary, those away from the power will form another world for themselves which has close contact with power and politics even though it is away from the power. However, the relationship between these two groups is done through ritual and special rules.

From a sociological perspective, we can focus on social contexts, structural changes as well as new social forces which their emergence in the political field makes this development possible (Rezai and Abdi, 1999: 7).

In general, the electoral behavior is a type of political action which is in relation with structural functions of economic, community and cultural subsystem at the macro-level of social system. This behavior is related to organism, personality, and social behavioral status and behavioral patterns in addition to the subsystem of the social system. Intimately, such behavior is related to the middle level of social system with technological bureaucratic, educational and symbolic conditions of social organization. In the meantime, if we consider the society as a social system which provides its functions based on the principle of structural resolution and consider the society as that type of social system that provides its functions based on the principle of structural integration, the diversity of electoral behavior can be ruled to be in two above formats. In this sense, the Electoral behavior is effected less by advertising in society and activities of the parties are not so effective on the behavior of voters because the voters have decided their votes before the start of election campaigns. Voters have constant political affiliations in social events and voting which re based on their behavioral patterns and are somewhat predictable.

\subsection{Rational choice pattern (rational choice)}

This pattern has been raised by Anthony Downs especially in a book entitled "The theory of democracy". Downs resembles political choices to economic choices. He states that people compare goods in terms of price and quality in the market and purchase goods which are economically affordable. People act the same in the politics market and vote for people or parties which answer to their needs in the best way (Ketabi, 1995: 161).

In this approach, voters select whichever programs announced by the candidates that support their interests. 
In general, researchers who believe in this pattern believe that voting is a personal decision which is independent of social status and emotions and party affiliations of voters because the votes take place based on states raised by the candidates during the election period. According to this approach, rational choice is rooted in social changes of the present era and is primarily the result of a new cortex in the scenes who did not have the right to vote before and were absent in the elections.

Presence of youth and women in the field of elections was along with new developments in the political participation. News issues including youth and women's affairs arise with presence of this new cortex in the political scene.

Kramer (1975: 65) states: voting is an action based on rational calculations and calculation of personal profit and loss. It can be understood from his contents that rational approach tends towards individualism thinking and epistemological individualism is used more in analysis of political phenomena and self-interest determines voters' behavior more than anything.

In fact, it can be stated that explanation of political phenomena using the self-interest variable and rational choice or the wise choice are among very old literature.

The Intellectual roots of this phenomenon goes back to political writings in ancient Greece and the Middle Ages and the resurgence of political thought in the eighteenth and nineteenth centuries through concepts of economic welfare, liberalism and utilitarianism, and the views of thinkers like Hobbs, Locke Mill and Adam Smith. Aristotle has used the rational choice in his works in detail especially in Nicomachean Ethics. He further noted in addition to involuntary and voluntary actions that achieving goals is possible through different ways, he notes that the Individualism of mentioned solutions is not the same and there is a hierarchy in level of individualism in different solution from the highest to the lowest. In fact, Aristotle wanted the policy makers of each society to pay attention to this individualism hierarchy of solutions and wants them to select the best possible way to achieve the goal of profitability (Aristotle, 1985: 67-69).

Tunis hem believes that the human behavior consists of organic and assessed will where the organic will is instinctive and emotional and assessed will is derived from abstract thinking and wisdom and search for power and serves the individual selfishness. He believe the fundamental properties of new communities to be in rational goaldirected actions and reasonable actions according to which, people prefer to be less involved in politics or society (Cazino, 1985: 25).

In this approach, the voter can be assumed as consumer of goods because he/she acts rational in selection of political good as same as rational act of selection of goods. The rudiments of such political behavior which is rational behavior is the concept of decision or choice. The decision maker must evaluate various options in selection of a candidate. Of course, the fact that the decision making is not only based on economic reasons is true because the selection from different choices based on their value or utility is the heart of the economic process. That is why some political scientists have sought to predict the behavior of the consumer in the political decision based on assumption that he/she acts rational as same of economists. It can be said that in this process the wise selector has confidential information about the situations and validity of candidates and matches those with his/her preferences and votes economy.

In general, in rational section approach, anyone chooses the option that has the highest benefits for him/her.

Voters seek four types of benefits to distribute power appropriately:

- Economic benefits (Maintain and enhance the purchasing power, employment, housing, use of the opportunities in enterprises and public institutions and ...).

- Cultural benefits (Free access to the information, Freedom in the production and consumption of cultural products).

- Political benefits (searching self-benefits using parties and groups, manifestation of self needs using democratic practices in the power structure).

- Economic benefits

In general, the public's perceptions of their own interests benefits and Candida who clams he/she can meet those are based on evaluation of people of past performance of candidate and personal, partisan, ethnic and tribal actions.

\section{Findings}

According to the results of table 1, the correlation between independent (The type of mobilization of resources at the disposal of candidates) and the dependent variable (victory of one candidate over other competitors) has been $70 \%$ using Pearson test. Since the significance level of the test is 0.000 , we can say with a high confidence that there is a significant 
correlation between the two variables which means the increased types of mobilization of resources at the disposal of candidates will increase the percentage of victory of one candidate over other competitors.

Table 1: Pearson's correlation coefficient between the type of mobilization of resources at the disposal of candidates and victory of one candidate over other competitors

\begin{tabular}{|c|c|c|}
\hline Variables & Correlation) $\mathrm{X}($ & Level of significance) $\mathrm{M}($ \\
\hline $\begin{array}{l}\text { The type of mobilization of resources at the disposal of candidates } \\
\text { Victory of one candidate over other competitors }\end{array}$ & $70 \%$ & 0.000 \\
\hline
\end{tabular}

According to the results of table 2, the correlation between independent (The type of political sources at the disposal of candidates) and the dependent variable (victory of one candidate over other competitors) has been $60 \%$ using Pearson test. Since the significance level of the test is 0.000 , we can say with a high confidence that there is a significant correlation between the two variables which means the increase types of political sources at the disposal of candidates will increase the percentage of victory of one candidate over other competitors.

Table 2: Pearson's correlation coefficient between the type of political sources at the disposal of candidates and victory of one candidate over other competitors

\begin{tabular}{lcc}
\hline Variables & Correlation) & $\mathbf{X}\left(\begin{array}{l}\text { Level of significance }) \\
\text { M( }\end{array}\right.$ \\
\hline The type of political sources at the disposal of candidates & $60 \%$ & 0.000 \\
Victory of one candidate over other competitors & & \\
\hline
\end{tabular}

According to the results of table 3, the correlation between independent (The type of cultural sources at the disposal of candidates) and the dependent variable (victory of one candidate over other competitors) has been $65 \%$ using Pearson test. Since the significance level of the test is 0.000 , we can say with a high confidence that there is a significant correlation between the two variables which means the increase types of cultural sources at the disposal of candidates will increase the percentage of victory of one candidate over other competitors.

Table 3: Pearson's correlation coefficient between the type of cultural sources at the disposal of candidates and victory of one candidate over other competitors

\begin{tabular}{|c|c|c|}
\hline Variables & Correlation) $\mathrm{X}($ & Level of significance) $\mathrm{M}($ \\
\hline $\begin{array}{l}\text { The type of cultural sources at the disposal of candidates } \\
\text { Victory of one candidate over other competitors }\end{array}$ & $65 \%$ & 0.000 \\
\hline
\end{tabular}

According to the results of table 4, the correlation between independent (The type of economic sources at the disposal of candidates) and the dependent variable (victory of one candidate over other competitors) has been $75 \%$ using Pearson test. Since the significance level of the test is 0.000 , we can say with a high confidence that there is a significant correlation between the two variables which means the increase types of economic sources at the disposal of candidates will increase the percentage of victory of one candidate over other competitors.

Table 4: Pearson's correlation coefficient between the type of economic sources at the disposal of candidates and victory of one candidate over other competitors

\begin{tabular}{|c|c|c|}
\hline Variables & Correlation) $\mathrm{X}($ & Level of significance) $\mathrm{M}($ \\
\hline $\begin{array}{l}\text { The type of economic sources at the disposal of candidates } \\
\text { Victory of one candidate over other competitors }\end{array}$ & $75 \%$ & 0.000 \\
\hline
\end{tabular}

According to the results of table 5 , the correlation between independent (The type of social sources at the disposal of candidates) and the dependent variable (victory of one candidate over other competitors) has been $80 \%$ using Pearson test. Since the significance level of the test is 0.000 , we can say with a high confidence that there is a significant correlation between the two variables which means the increase types of social sources at the disposal of candidates will increase the percentage of victory of one candidate over other competitors. 
Table 5: Pearson's correlation coefficient between the type of social sources at the disposal of candidates and victory of one candidate over other competitors

\begin{tabular}{lcc}
\hline Variables & Correlation) & $\mathbf{X}\left(\begin{array}{l}\text { Level of significance }) \\
\hline \text { The type of }\end{array}\right.$ \\
Victory of one candidate over other competitors & $80 \%$ & 0.000 \\
\hline
\end{tabular}

All independent variables (mobilization of resources, political resources, cultural resources, economic resources and social resources) were entered into the regression program to carry out the regression analysis of victory of one candidate over other competitors.

From the total of four variable entered into the program regression using Enter method, all of the variables were entered into the equation for

Table 6: Determining the amount of the dependent variable (the victory of a candidate over competitors) by the remaining variables in the regression equation the regression effect coefficient which their explanation and interpretation and effect on the dependent variable are provided below:

The value for multivariate regression correlation coefficient $(R=0.786)$ shows a strong correlation of the set of independent variables and the dependent variable. The value for coefficient of determination $\left(R^{2}=0.618\right)$ shows a ration than average of dependent variable's variance by four independent variables of the research which means by entering all of the variables, about 62 percent of variability of victory of a candidate over other competitors is determined by these factors.

Table 6: The level of determination of the dependent variable (the victory of a candidate over other competitors) by the remaining variables in the regression equation

\begin{tabular}{|c||c||c|c||c|}
\hline Model & $\mathrm{R}$ & $\mathrm{R} 2$ & Adjust RScuare & Std.Error of the Estimate \\
\hline \hline 1 & 0.786 & 0.718 & 0.604 & 0.45579 \\
\hline \hline
\end{tabular}

According to table 7, Fisher's test value equal to 43.213 which is in a completely significant level $(P<0.02)$ indicates a significant relation between the dependent variable (the victory of one candidate over other competitors) and the set of remaining variables in the equation

Table 7: Variance analysis of significance of the model

\begin{tabular}{ccccccc}
\hline & Model & Root set & Degrees of freedom & mean squares & $\underline{F}$ & $\underline{\text { Sig }}$ \\
\hline 1 & Regression & 35.998 & 4 & 8.997 & 22.229 & 0.000 \\
Remaining & 38.452 & 95 & 0.405 & & \\
\hline & Total & 74.440 & 99 & & & \\
\hline
\end{tabular}

According to table 8 , the most important variables influencing directly on the victory of one candidate over other competitors are respectively economic resources, political resources, cultural resources and social resources and we will evaluate the quality of independent variables and their effect on the victory of one candidate over other competitors in below:

The optimal use of "economic resources" variable has had the highest effect on the victory of one candidate over other competitors (with the factor equal to 0.233 ). Thus, the victory of one candidate over other competitors take the highest effect from the optimal use of "economic resources" variable which means the more optimal use of economic resources in planning will the chance of outshining other competitors. In other words, the percentage of victory of one candidate over other competitors will increase by 0.233 for each unit of increase in economic resources.

The second variable which has had the highest effect on the variable of victory of one candidate over other competitors is "Political sources" (Beta $=0.171$ ) which means the better planning of political resources, will increase the chance of victory of one candidate over other competitors. In other words, the percentage of victory of one candidate over other competitors will increase by 0.171 for each unit of increase in Political resources.

The third variable entered the equation based on the Beta weight is "cultural resources" variable. Its Standardized 
regression effect coefficient (Beta) is equal to 0.114 . According to this result, it can be said that the percentage of victory of one candidate over other competitors will increase by 0.114 for each unit of increase in cultural resources.

The fourth variable entered the equation based on the Beta weight is "Social resources" variable. Its Standardized regression effect coefficient (Beta) is equal to 0.100 . According to this result, it can be said that the percentage of victory of one candidate over other competitors will increase by 0.100 for each unit of increase in Social resources.

Table 8: Multivariate regression to identify (predict) Factors affecting the knowledge management

\begin{tabular}{lccccc}
\hline Variable & $\underline{B}$ & $\underline{\text { SEB }}$ & $\underline{\text { Beta }}$ & $\underline{\underline{T}}$ & $\underline{\text { Sig }}$ \\
\hline Economic resources & .233 & .054 & .292 & 4.311 & .000 \\
Political sources & .171 & .037 & .235 & 4.596 & .000 \\
Cultural Resources & .114 & .053 & .182 & 3.040 & .003 \\
Social resources & .100 & .049 & .152 & 2.441 & .015 \\
\hline Constant & .229 & .147 & & 1.555 & .121 \\
\hline
\end{tabular}

\section{Conclusion}

Participation in elections is one of the political actions. A lot of countries in the world consider the Free, Healthy election commensurate with the national structures and national interests as a priority in today's changing world to institutionalize civil patterns and form state and public institutions with direct vote of people.

Participation of people in the elections is affected by many factors and creates a certain type of behavior at any moment which is called the electoral behavior. A lot of factors are also effective in the type of electoral behavior of Iranian people. Internal attributes and characteristics of Iranian society and the general atmosphere in the country are affective in this behavior. Also the failed experience of institutions such as political parties shaping electoral behavior of the Iranian people has reduced political participation of people and in absence of political institutions, other elements affect the victory of one candidate over other competitors and voting behavior of people. This behavior is sometimes hidden and its emergence in elections period creates a type of surprise in minds. Believing in unpredictability of electoral behavior of the Iranian people is also derived from the same matter. Thus, the mobilization of resources has referred to several independent variables in this article in victory of one candidate over other competitors which includes management of political resources, cultural resources, economic resources and social resources.

The main objective of this research has been identification and determination of the type of resources available to candidates and its relation with the victory of one candidate over other competitors. We benefited from library and survey methods for the purposes of research and testing the arising hypotheses. A questionnaire with 15 questions was developed in survey method which was distributed between a hundred of intellectuals, professors and specialists in the political field and ultimately, the questionnaires were analyzed in spss software after collection.

In general, the Pearson correlation test was used to determine the relationship between independent and dependent variables where all four hypothesis of the research had a relatively severe and significant relationship and the multivariate regression test was used to evaluate the level of effectiveness of independent variables on the dependent variable which was obtained using enter method. The value for Multivariate regression correlation coefficient $(R=0.786)$ shows the strong correlation of the set of independent variables and the dependent variable. Coefficient of determination $\left(R^{2}=0.618\right)$ indicate the higher than normal ratio of dependent variable's variance by four independent variable of the research, This means that by inclusion of all independent variables, about 62 percent of the variability of the victory of a candidate over to other competitors is determined by these factors and candidates increase their victory percentage by managing the independent variables. However, one thing should be noted that the $62 \%$ coefficient of determination indicates that only 62 percent of one hundred percent of influencing factors are predicted by these factors and 38 percent of victory of one candidate over other competitors are related to other independent factors which have not been discovered in this research and depend on other variables which must be obtained through further studies.

\section{References}

Aristotle (1986). «Nicomachean Ethics», translated by of Seyed Abolghasem Poorhosseini, Tehran: Tehran University.

Ariyai, Masoud. (1997). "Institutions of Political Socialization", Hamshahri, No. 1347, fifth year.

Ayoubi, Hojatollah. (1998)"Electoral Behavioral Analysis" political - economic information, numbers 137-138.

Ayoubi, Hojatollah (2003). "Electoral participation; causes and motives "Rooz, No. 9. 
Rush, Michael (1998). Society and politics, translated by Manouchehr Sabouri, Tehran: Samt.

Rezaei, Abdul Ali Abbas Abdi (1999). Sociological analyzes of the events of the second day of June ", Tehran: Tarhe No, No. 7.

Jean Cazeneuve (1985). The power of television, translated by Ali Asadi, Tehran: Amir Kabir.

Darabi, Ali (2009). Electoral Behavior in Iran, Models and Theories, Tehran: Soroush.

Saroukhani, Bagher. (2006). Research methods in social sciences, Volume I, Second Edition, Tehran: Institute for Humanities.

Serajzadeh, Seyed Hossein (2004). "Challenges of religion and modernity, religious and sociological debates on secularization", Tehran: Tarhe No.

Salamat Panah, Morteza. (2002). Factors affecting on the popular vote in elections with a case study in the City Council of Mazandaran province, "MA thesis, Qom: Mofid University.

Taleban, Mohammad Reza (2001). Family, university and socialization of the youth, social science, Scientific - Research Journal, No. 13 , spring and summer $27-54$.

Alikhani, Ali Akbar. (1998). Political participation, researches, Tehran: Safir.

Ketabi, Mahmoud (1995). Principles and policies of the new government, Esfahan: Golbahar.

Marsh, David and Gerry Stoker. (1999). Method and theory in political science, translated by Amir Mohammad Haji Yousefi, Tehran: Strategic Studies.

Mehrdad, Hormoz. (1999). Political socialization, Tehran: Pazhang.

Lazarsfeld, Paul (1994). Bbernard BERELSON, Hazel GAUDET, The Peoples Choice, Columbia University Press. 